\title{
Pengaruh Penggunaan Bot Werewolf Telegram pada Penguasaan Kosakata Siswa Sekolah Menengah Atas
}

\author{
The Effect of Using Werewolf Telegram Bot on Senior High School Students' \\ Vocabulary Mastery
}

\author{
Wildan Hariz ${ }^{1}$, Dadang Sudana ${ }^{2}$ \& Wawan Gunawan ${ }^{3}$ \\ 1,2,3 Universitas Pendidikan Indonesia, Bandung, Jawa Barat, Indonesia \\ wildanhariz27@gmail.com
}

Naskah diterima tanggal 07/08/2021, direvisi akhir tanggal 12/08/2021, disetujui tanggal 14/08/2021

\begin{abstract}
Abstrak
Masalah dalam mempelajari kosakata melalui messenger instan berakar dari kurangnya adaptasi kontekstualisasi yang menjadi tujuan multimedia. Walaupun penelitian tentang messenger instan menunjukan pengaruh positif pada penguasaan kosakata, keberadaan bot diharapkan bermanfaat dalam mengadaptasi kontekstualisasi pembelajaran kosakata khususnya dalam membaca. Penelitian ini bertujuan untuk meneliti penggunaan Bot Werewolf Telegram dalam pembelajaran bahasa Inggris, terutama dalam penguasaan kosakata, sebagai salah satu implikasi pedagogis yang disimpulkan berdasarkan isu-isu dari kemajuan teknologi saat ini. Penelitian ini menggunakan metode kuasi-eksperimental dan teknik purposive sampling dengan instrumen tes penguasaan kosakata. Eksperimen dalam penelitian ini melibatkan 60 siswa SMA untuk berinteraksi di grup chat dengan serangkaian bot di Telegram. Data dianalisis secara kuantitatif dengan menggunakan kerangka penguasaan kosakata melalui interaksi siswa dalam aplikasi. Hasil analisis menunjukkan bahwa terdapat perbedaan yang signifikan antara penggunaan Bot Werewolf Telegram dan placebo treatment pada penguasaan kosakata siswa SMA. Hal ini mengimplikasikan penggunaan Bot Werewolf Telegram dapat meningkatkan kemampuan kosakata siswa SMA secara positif dan mempermudah identifikasi karakteristik kosakata yang dipelajari siswa agar sesuai dengan tujuan instruksional kurikulum dalam konteks pembelajaran bahasa Inggris sebagai bahasa asing.
\end{abstract}

Kata Kunci: Bot, Penguasaan Kosakata, SMA, Telegram, TIK.

\begin{abstract}
Problems in learning vocabulary through instant messenger seem to take root in the lack of adaptable contextualization which the multimedia aims to facilitate. Although research on the use of instant messengers show positive effects on vocabulary mastery, the existence of bots may be useful in adapting the contextualization of learning vocabulary, especially in reading. This paper aims to investigate the use of Werewolf Telegram Bot in learning English, especially in vocabulary mastery, as one of the pedagogical implications concluded from the burning issues of technological advancement. To collect the data, the study employed quasi-experimental method and purposive sampling technique with a vocabulary mastery test. The study involves 60 senior high school students who interact in a group chat with a set of bots in Telegram. The data were analyzed quantitatively in terms of vocabulary mastery through the students' interaction within the application. The results of the analysis reveal that there is a significant difference between using Werewolf Telegram Bot and the placebo treatment on senior high school students' vocabulary mastery. The findings in current research imply that the use of Werewolf Telegram Bot positively improve senior high school students'vocabulary mastery and allow identification of vocabulary characteristics that the students learn as instructional goal in the curriculum in English as Foreign Language context.
\end{abstract}

Keywords: Bot, ICT, Senior High School, Telegram, Vocabulary Mastery.

How to cite (APA Style) : Hariz,W., Sudana,D., \& Gunawan,W. (2021). Pengaruh Penggunaan Bot Werewolf Telegram pada Penguasaan Kosakata Siswa Sekolah Menengah Atas. Jurnal Penelitian Pendidikan, 21 (2), 2021. 12-24. doi: https://doi.org/ 10.17509/jpp.v21i2.37421 


\section{PENDAHULUAN}

Penguasaan kosakata bahasa Inggris telah menjadi perhatian yang luas di Indonesia. Jika siswa memiliki penguasaan kosakata bahasa Inggris yang rendah, hal itu akan menghambat mereka dalam mempelajari keterampilan reseptif dan produktif sebagai isi utama dari pelajaran bahasa Inggris di sekolah. Untuk membantu siswa SMA mengatasi penguasaan kosakata, kemajuan teknologi memberikan beberapa alternatif dan solusi. Salah satunya dengan adanya messenger instan. Menurut Prensky (2001), siswa di era ini dianggap sebagai penutur asli bahasa digital internet dan komputer. Para siswa berhasil mengadopsi teknologi instruksional baru dalam pembelajaran mereka dan membangun pondasi penguasaan kosakata.

Seiring hal tersebut, hal yang sangat menarik adalah integrasi TIK dalam pembelajaran bahasa tidak hanya memengaruhi metodologi untuk mengajar siswa. Dalton dan Grisham (2011) menemukan bahwa, meskipun memberikan kemudahan dalam memilih metode yang cocok untuk pelajar, TIK juga berfungsi sebagai perangkat dan sumber daya teknologi yang beragam. Sumber daya ini digunakan untuk berkomunikasi, membuat, menyebarkan, menyimpan, dan mengelola informasi. Fungsi-fungsi ini tampak lebih jelas dalam penggunaan Telegram sebagai media pengajaran di Iran dan Uzbekistan (Niyayesh, 2015).

Ketika popularitas Telegram meningkat, Mashhadi, dan Kaviani (2016) menyelidiki dampak sosial Telegram sebagai jejaring sosial dalam pengajaran bahasa Inggris. Dampak dari aplikasi ini tercermin dalam pengalaman baik pelajar EFL menengah Iran ketika mereka belajar kosakata. Sementara itu di Uzbekistan, Karimov dan Kim (2017) pun mengidentifikasi beberapa faktor yang memengaruhi pengguna Telegram dalam hal karakter dan perilaku siswa. Kemudian, akhirnya Movafagh (2017) menemukan bahwa ada korelasi antara penggunaan Telegram dan pembelajaran kosakata pelajar EFL Iran. Sebuah studi kuasi-eksperimental oleh Alakrash, et al. (2020) mengedepankan efektivitas Telegram secara umum tanpa bantuan bot. Meski begitu, konteks fungsi kosakata tersebut terlalu luas untuk diterapkan dalam konteks EFL Indonesia. Selain itu, efek penggunaan bot di Telegram masih belum terungkap dalam penelitian terkini dan serupa tentang Telegram meskipun platform tersebut merupakan platform belajar-mengajar yang terbukti efektif (Xodabande, 2017; Nafis, et al., 2018; Abu-Ayfah, 2019; Faramarzi, et al., 2019; Wiranegara, D. \& Hairi, 2020; Kayzouri et al., 2020).

Terlepas dari temuan-temuan ini, bagaimana fungsi kosakata dalam kegiatan membaca yang harus memenuhi tujuan instruksional dalam Pendidikan Indonesia masih belum jelas. Dalam beberapa tahun terakhir, Indonesia telah mereformasi program penerimaan mahasiswa universitas negeri menjadi Ujian Tertulis Berbasis Komputer (UTBK). Sebagai contoh, pada tahun 2019, pengelolaan penerimaan mahasiswa dilakukan oleh panitia di masing-masing pemerintah daerah. Sebab sekarang terpusat dan online, melalui mereka bekerja sama dengan perguruan tinggi negeri di semua daerah. Dalam UTBK terdapat dua jenis tes, yaitu tes potensi skolastik (TPS) dan tes potensi akademik (TPA). Bahasa Inggris termasuk dalam TPS karena ditujukan untuk mengukur kemampuan kognitif yang dianggap penting untuk keberhasilan di sekolah formal, khususnya pendidikan tinggi. Di TPS, yang akan diuji adalah kemampuan penalaran umum, kemampuan kuantitatif, pengetahuan dan pemahaman umum, serta kemampuan membaca dan menulis (Permendiknas, 2018; Syakriah, 2019). Terdapat delapan pertanyaan pada dua bacaan yang termasuk dalam bagian bahasa Inggris UTBK 2019. Hal ini tampaknya menjadi alasan lebih bagi siswa di SMA untuk menguasai kosakata dalam persiapan UTBK, karena penguasaan kosakata hadir dalam konteks membaca yang akan diuji sebagai salah satu tujuan akhir pembelajaran bahasa Inggris di SMA.

Dengan mempertimbangkan teknologi, guru dapat memberikan materi yang menantang kepada siswa, terutama ketika mengajar membaca untuk UTBK yang oleh sebagian guru dianggap lebih sulit 
karena siswa cenderung memiliki motivasi yang rendah dalam kegiatan membaca (Rahimi \& Yadollahi, 2011). Namun, penyesuaian tampaknya perlu dilakukan agar materi tidak membebani siswa atau tidak terlalu mudah bagi mereka. Penelitian telah menunjukkan bahwa keterlibatan messenger instan dalam pembelajaran bahasa dapat menumbuhkan minat dan latar belakang pengetahuan siswa dalam mempelajari kosa kata baru. Namun, karakteristik kosakata yang dipelajari dengan aplikasi tersebut belum terungkap dengan jelas. Ada beragam messenger tersedia untuk membantu menguasai kosakata bahasa Inggris. Beberapa di antaranya adalah WhatsApp, Line, Discord, Yahoo! Messenger, dan Telegram (Amry, 2014; Cakir, 2015; Alhawiti, 2015).

Namun demikian, dibandingkan dengan messenger obrolan instan lain yang ada hingga saat ini, Telegram tampaknya memiliki fitur lebih fleksibel. Salah satu fitur mutakhir utama di Telegram adalah bot yang dapat diaktifkan sebagai game atau ensiklopedia pendukung dalam belajar bahasa Inggris. Telegram unggul kecepatan akses dan ruang memori yang besar. Selain itu, dengan Telegram, pengguna dapat berbagi video hingga $1 \mathrm{~GB}$, mengirim banyak foto sekaligus, dan mengirim semua media lain dengan cepat. Semua pesan disimpan di cloud, sehingga siswa dapat mengaksesnya dengan mudah dari perangkat mereka. Berdasarkan teori di atas dan kondisi saat ini, penelitian ini mencoba untuk menyelidiki penguasaan kosakata bahasa Inggris siswa SMA beseerta karakteristiknya melalui penggunaan Bot Werewolf Telegram dalam konteks bahasa Inggris sebagai bahasa asing (English as a foreign language-EFL) di Indonesia.

\section{METODE PENELITIAN}

\section{Tujuan Penelitian}

Adanya kesenjangan dalam hasil-hasil penelitian terdahulu mengenai pengaruh platform media sosial, messenger instan, dan pengaruh bot dalam proses pembelajaran bahasa Inggris telah memotivasi peneliti dalam membentuk tujuan penelitian yang lebih terarah, yaitu mengungkap pengaruh dari penggunaan Bot Werewolf Telegram. Pengaruh tersebut ditinjau dari segi penguasaan kosakata dan konteks membaca teks, sebagai salah satu implikasi pedagogis yang disimpulkan dari isu-isu kemajuan teknologi dan pembelajaran bahasa Inggris dalam masa pandemi. Maka dari itu, rumusan tujuan penelitian ini disusun sebagai berikut.

1. Untuk mengetahui pengaruh Werewolf Telegram Bot terhadap penguasaan kosakata bahasa Inggris siswa SMA.

2. Untuk mengidentifikasi karakteristik kosakata yang dipelajari siswa SMA melalui Bot Werewolf Telegram.

\section{Rancangan Penelitian}

Dalam upaya mencapai tujuan penelitian di atas, desain kuasi-eksperimental digunakan sebagai metode penelitian ini. Berdasarkan desain ini, peneliti menggunakan purposive sampling dengan tugas non-acak berupa tes yang melibatkan sesi Bot Werewolf Telegram dan placebo treatment untuk mengetahui pengaruh penggunaan bot tersebut pada penguasaan kosakata siswa SMA. Selanjutnya, pengkategorian kosakata berdasarkan kurikulum dilakukan dalam upaya untuk mengungkapkan karakteristik kosakata yang dipelajari oleh siswa melalui Bot Werewolf Telegram. Selain itu, chat log berisi aktivitas siswa di Telegram menjadi data sekunder untuk memberikan wawasan yang lebih jelas tentang karakteristik kosakata. Kerangka analisis yang digunakan pada penelitian ini didasarkan pada British National Corpus Bauer dan Nation (1993) yang telah dikembangkan oleh Heidari dan Onvani (2018) serta digunakan dalam penelitian Ghobadi dan Taki (2018). 


\section{Pengumpulan Data}

Dalam penelitian ini, partisipan dipilih dan dibagi menjadi dua grup. Jumlah seluruh partisipan adalah 60 siswa, yang terbagi menjadi 30 siswa dalam grup eksperimental dan 30 siswa dalam grup kontrol. Partisipan adalah siswa kelas satu di sebuah SMA di Bandung, Indonesia. Pemilihan siswa kelas satu ini sejalan dengan penggunaan bot Telegram yang sangat mengandalkan teks, terutama teks naratif dan recount yang diajarkan di kelas satu SMA. Sedangkan jumlah peserta yang terlibat didasarkan pada pertimbangan untuk meminimalkan kesalahan agar hasil yang terjadi tidak hanya disebabkan kebetulan semata (Sugiyono, 2017). Oleh karena itu 60 peserta dianggap cukup untuk penelitian kuasi-eksperimental ini.

Untuk menggambarkan rancangan penelitian dan pengumpulan data di atas, uraian langkahlangkah penelitian disajikan pada gambar berikut.

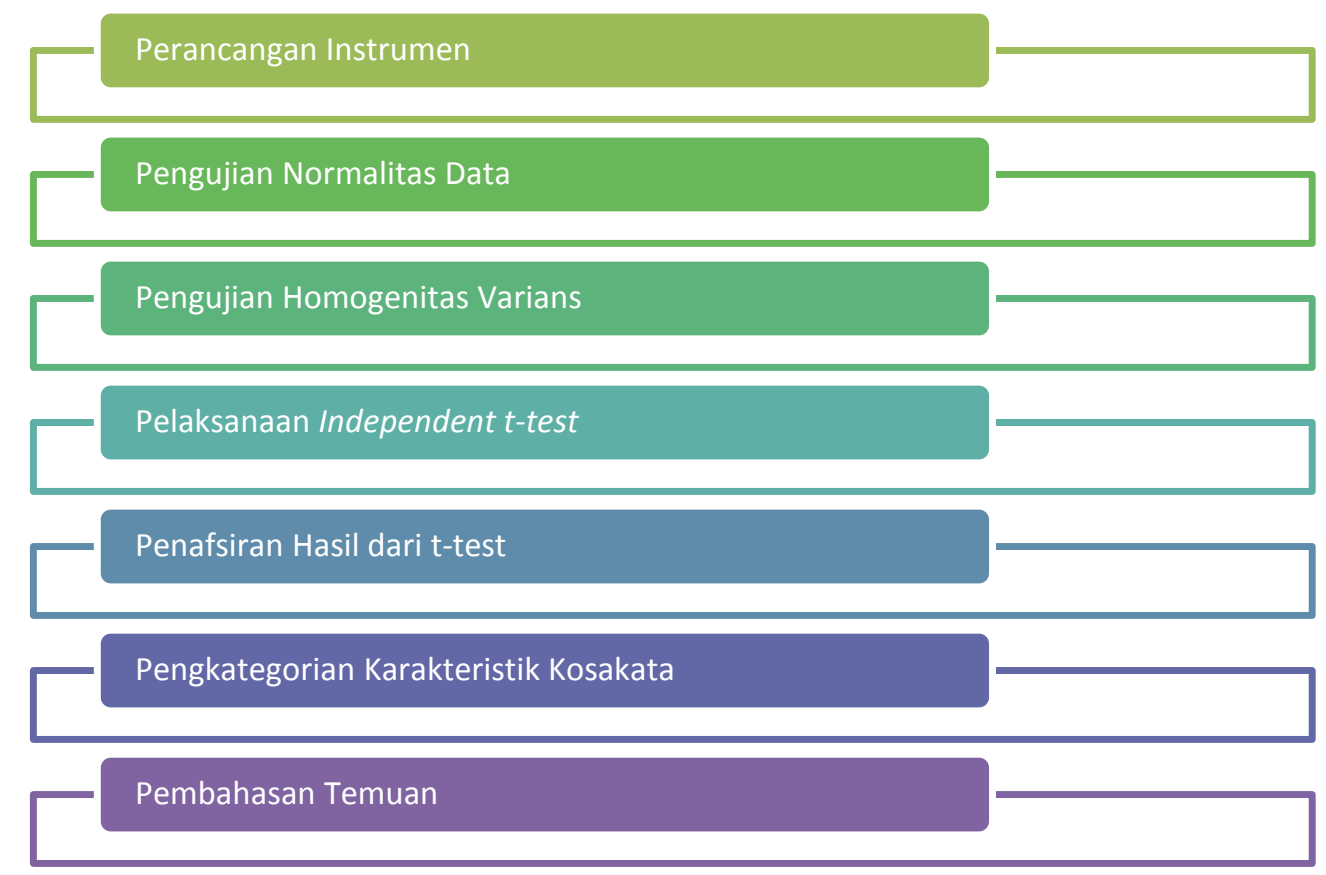

Gambar 1. Rancangan kuasi-eksperimental dengan independent t-test yang diadaptasi dari Sugiyono (2017)

Pilot test dilaksanakan sebelum pre-test untuk menjaga validitas dan reliabilitas instrumen tes yang digunakan pada penelitian ini. Tes berupa pilihan ganda dan pilihan benar-salah. Tes ini terbagi menjadi 20 butir pada Bagian 1, 40 butir pada Bagian 2, dan 20 butir pada Bagian 3. Bagian 1 mengukur seberapa luas ukuran kosakata yang diketahui siswa, Bagian 2 mengukur kedalaman kosakata yang diketahui siswa. Bagian 3 mengukur kemampuan siswa mahami kosakata dalam konteks bacaan yang di dalamnya terbagi menjadi 10 butir pilihan ganda dan 10 pilihan benar-salah berbasis teks.

Setelah pilot test dilaksanakan, revisi dilakukan pada test dengan mempertimbangkan Indeks Kesulitan dan Kekuatan Pembeda pada setiap butir soal. Kemudian, tes digunakan dalam pre-test pada dua grup sampel yang telah diuji normalitas data dan homogenitas varians-nya. Setelah itu, partisipan dalam grup eksperimental diberi treatment berupa sesi Bot Werewolf Telegram selama 6 kali, sementara partisipan dalam grup kontrol diberikan placebo treatment berupa teknik konvensional reading aloud. Kemudian, post-test dilaksanakan dengan rancangan tes dan prosedur pengujian 
normalitas data dan homogenitas varians yang sama dikarenakan pengujian tersebut adalah syarat untuk dilakukannya Independent t-test. Hasil dari penghitungan nilai $t$ kemudian ditafsirkan dengan alpha value 0.05, sementara kosakata yang dipelajari dikategorikan berdasarkan chat log dan hasil post-test. Terakhir, temuan dibahas berdasarkan kerangka analisis dan teori serta hasil temuan penelitian sebelumnya.

\section{Analisis Data}

Berbeda dari desain eksperimen biasa, dalam studi kuasi-eksperimental, manipulasi variabel independen tetap terlibat tanpai penugasan acak. Alasan penelitian ini menggunakan desain kuasieksperimental adalah desain ini dapat membantu peneliti untuk mengetahui pengaruh media atau teknik pembelajaran tertentu terhadap perilaku subjek - atau dalam hal ini, penguasaan kosakata siswa. Memang, selalu ada kekhawatiran tentang kesetaraan dua atau lebih grup karena tugas acak tidak ada. Namun demikian, perbedaan antara kedua grup dapat disebabkan oleh perlakuan yang hanya diterima oleh grup eksperimental atau perbedaan antara partisipan dalam kedua grup (Carr, 2011). Oleh karena itu, penting bagi peneliti untuk meminimalkan perbedaan partisipan dengan memilih partisipan yang semirip mungkin untuk kedua grup.

Selanjutnya desain sampel independen dengan dua grup dianalisis dengan independent t-test. Hasil uji $t$ adalah skor standar yang mencerminkan besarnya selisih rata-rata kedua grup. Setelah itu, hasilnya digunakan untuk menentukan probabilitas apakah perbedaan itu hanya karena kebetulan atau tidak (Griffe, 2012). Jika nilai probabilitasnya cukup rendah, maka peneliti dapat menolak hipotesis nol dan menerima hipotesis alternatif. Dengan kata lain, peneliti dapat menyimpulkan bahwa terdapat pengaruh yang signifikan dari penggunaan Bot Werewolf Telegram pada penguasaan kosakata siswa SMA. Maka dari itu, hipotesis nol dan hipotesis alternatif dalam penelitian ini dinyatakan sebagai berikut.

$\mathrm{H}_{0}$ : Tidak terdapat perbedaan yang signifikan antara penggunaan Bot Werewolf Telegram dan placebo treatment pada penguasaan kosakata siswa SMA.

Sementara itu, $\mathrm{H}_{\mathrm{a}}$ dari penelitian ini adalah:

$\mathrm{H}_{\mathrm{a}}$ : Terdapat perbedaan yang signifikan antara penggunaan Bot Werewolf Telegram dan placebo treatment pada penguasaan kosakata siswa SMA.

Sebagai tambahan, penghitungan dependent t-test dan Ukuran Efek juga dilakukan pada data yang diambil dari grup sampel. Dependent t-test dilakukan untuk mengetahui arah hubungan antara hasil skor pre-test dan post-test, sementara Ukuran Efek dihitung untuk mengukur ukuran kekuatan efek relatif dari Bot Werewolf Telegram terhadap kosakata siswa SMA.

\section{HASIL DAN PEMBAHASAN Hasil}

Dalam penelitian ini, analisis data dibagi menjadi empat bagian. Bagian pertama adalah analisis skor pre-test, kedua adalah analisis skor post-test, ketiga adalah analisis dependent t-test, dan terakhir adalah analisis ukuran efek Bot Werewolf Telegram .

Pada Tabel 1 menunjukkan bahwa rata-rata grup eksperimental adalah 53,537. Di sisi lain, ratarata grup kontrol adalah 50,845. Selanjutnya simpangan baku grup eksperimental sebesar 9,599 dan simpangan baku grup kontrol sebesar 7,631. Dengan kata lain, ada perbedaan 1,308 antara rata-rata kedua grup, dengan sedikit selisih 2,692 dalam simpangan baku. Dengan demikian, dapat disimpulkan dari kolom mean bahwa selisih nilai minimum dan maksimum yang dihasilkan oleh siswa mencerminkan seberapa baik dan mirip mereka mengerjakan tes di setiap grup. 
Sebagai prasyarat independent $t$-test, nilai pre-test baik grup eksperimental maupun kontrol diharapkan homogen dan terdistribusi normal. Oleh karena itu, independent t-test pertama yang diberikan memastikan bahwa skor awal kedua grup tidak terlalu berbeda dalam hal penguasaan kosakata yang ditunjukkan oleh nilai simpang baku yang mirip di atas.

Perhitungan two-tailed independent t-test dalam SPSS memberikan informasi yang terdiri dari nilai $t$ dan $p$ (lihat Tabel 1). Karena varians yang sama diasumsikan, skor pre-test pada grup eksperimental dan skor pre-test pada grup kontrol, terungkap bahwa tidak ada perbedaan signifikan pada hasil antara grup eksperimental dan kontrol.

Tabel 1 Independent t-test pada Pre-test

\begin{tabular}{cccccc}
\hline Grup & N & Mean & SD & t-value & p-value \\
\hline Kontrol & 30 & 53,537 & 9,599 & \multirow{2}{*}{$0,0,946$} & \multirow{2}{*}{0,380} \\
\hline Eksperimental & 30 & 50,845 & 7,631 & & \\
\hline
\end{tabular}

Secara rinci, nilai $t$ yang diperoleh $\left(t_{o b t}\right)$ saat varians dinyatakan sama adalah $-0,946$. Setelah dikonsultasikan dengan tabel distribusi $t$ ternyata nilai tersebut tidak melebihi nilai kritis tabel $\left(t_{c r i t}\right)$ sebesar 2,045 pada degree of freedom $(\mathrm{df})=29$ dengan taraf signifikansi 0,05 (alpha value). Hasil ini menunjukkan bahwa nilai yang diperoleh siswa pada kedua grup tidak terlalu berbeda karena $t_{o b t}=-$ $0,946<t_{\text {crit }}=2,045$ dengan $p=0,380>0,05$. Nilai $t$ negatif berarti terdapat pembalikan arah pada pengaruh treatment yang tidak berpengaruh terhadap perbedaan signifikansi kedua grup. Sehingga, dapat disimpulkan bahwa tidak ada perbedaan yang signifikan antara kedua grup dalam hal penguasaan kosakata siswa seperti yang diungkapkan oleh hasil pre-test.

Pada Tabel 2, hasil komputasi statistik deskriptif menunjukan peningkatan nilai mean dan simpangan baku pada hasil post-test dibandingkan dengan hasil pre-test. Hasil dari penghitungan independent $t$-test dapat dilaporkan sebagai $t(29)=-2,449, \mathrm{p}=0,110$.

Tabel 2 Independent $t$-test pada Post-test

\begin{tabular}{cccccc}
\hline Grup & N & Mean & SD & t-value & p-value \\
\hline Kontrol & 30 & 76,311 & 3,077 & \multirow{2}{*}{0,011} \\
\hline Eksperimental & 30 & 76,843 & 6,927 & \\
\hline
\end{tabular}

Secara keseluruhan, data skor hasil post-test menunjukkan bahwa perbedaan rata-rata skor antara grup kontrol dan grup eksperimen secara statistik berbeda pada tingkat signifikansi 0,05 dengan $\mathrm{df}=29$. Setelah nilai $t$ dikonsultasikan ke tabel distribusi $t$ untuk df yang sesuai, ternyata nilai $t$ yang diperoleh mengindikasikan adanya perbedaan signifikan dalam data skor hasil post-test. Hal ini ditunjukan oleh $t_{o b t}=-2,449>t_{c r i t}=-2,045$. dengan $p=0,011<0,05$. Akibatnya, hipotesis nol yang menyatakan tidak terdapat perbedaan yang signifikan antara kedua grup ditolak. Maka dari itu, dapat disimpulkan bahwa hipotesis alternatif yang menyatakan terdapat perbedaan yang signifikan antara penggunaan Bot Werewolf Telegram dan placebo treatment pada penguasaan kosakata siswa SMA diterima.

Hasil perhitungan menunjukkan rata-rata sampel berpasangan dalam adalah 63,758. Nilai ini mengindikasikan adanya peningkatan skor pada grup eksperimental setelah penggunaan Bot Werewolf Telegram. Selanjutnya, peningkatan nilai rata-rata antara pre-test dan post-test dihitung menggunakan dependent t-test sehingga menghasilkan nilai $t_{o b t}=2,955$ dengan $p=0,024$. Dengan demikian, perbandingan nilai $t$ dengan tabel distribusi $t$ mengindikasikan terdapat perbedaan dalam skor pre-test dan post-test karena $t_{o b t}=2,955>t_{\text {crit }}=-2,045$ pada $\mathrm{p}=0,024<0,05$ dengan $\mathrm{df}=29$. Hal ini membuktikan bahwa terdapat perbedaan signifikan di antara skor yang siswa hasilkan pada saat pre- 
test dan post-test dalam grup eksperimen setelah penggunaan Bot Werewolf Telegram. Oleh karena itu, hipotesis nol dependent $t$-test ini menyatakan bahwa tidak ada perbedaan yang signifikan antara kedua sampel yang berpasangan, maka hipotesis nol ditolak dan hipotesis alternatif diterima, yaitu ada perbedaan yang signifikan antara kedua sampel yang berpasangan. hasil dependent t-test dan Ukuran Efek dari treatment Bot Werewolf Telegram yang disajikan pada Tabel 3.

Tabel 3 Dependent t-test pada Pre-test dan Post-test

\begin{tabular}{cccccc}
\hline Grup & N & Mean & SD & t-value & p-value \\
\hline $\begin{array}{c}\text { Pre-test \& } \\
\text { Post-test }\end{array}$ & 30 & 63,758 & 4,346 & 2,955 & 0,024 \\
\hline
\end{tabular}

Sementara itu, penghitungan Ukuran Efek dilakukan secara manual dengan rumus berikut.

$$
\begin{gathered}
r=\sqrt{\frac{t^{2}}{t^{2}+d f}} \\
r=\sqrt{\frac{2,955^{2}}{2,955^{2}+29}} \\
r=0,572
\end{gathered}
$$

Gambar 2. Penghitungan Ukuran Efek

Pada Gambar 2, nilai $r$ menunjukkan koefisien ukuran efek relatif dari treatment Bot Werewolf Telegram pada penguasaan kosakata siswa SMA. Koefisien tersebut didapatkan dengan menggunakan nilai $t$ dan df dari independent $t$-test melalui rumus Cohen (1992) yang tertera di atas. Berdasarkan hasil penghitungan, ukuran efek relative dari penggunaan Bot Werewolf Telegram terhadap nilai pre-test dan post-test siswa adalah 0,572. Ketika koefisien $r$ dikonsultasikan ke tabel ukuran efek relatif yang dibuat oleh Cohen (1992), nilai tersebut dianggap termasuk kategori ukuran relatif sedang karena koefisien melebihi 0,5. Sehingga, seperti yang terindikasi pada tabel, dapat disimpulkan bahwa ukuran efek relatif medium dari penggunaan Bot Werewolf Telegram dalam grup eksperimental memiliki kekuatan pengaruh $69 \%$ di atas rata-rata grup kontrol.

\section{Pembahasan}

Pengaruh Bot Werewolf Telegram

Tujuan utama penelitian ini adalah untuk mengetahui pengaruh Bot Werewolf Telegram pada penguasaan kosakata siswa SMA. Untuk mengetahui hal tersebut, enam sesi pembelajaran dengan Bot Werewolf Telegram telah dijalani siswa sesuai dengan rancangan penelitian. Sejak pandemi dimulai pada awal tahun 2020, siswa di Indonesia harus beradaptasi dengan pembelajaran jarak jauh. Namun, beberapa penyesuaian harus dilakukan pada desain penelitian untuk mengakomodasi siswa dan untuk mendapatkan jumlah peserta yang cukup dengan data yang lebih valid dan andal. Akhirnya, pelaksanaan independent t-test pada skor yang diperoleh siswa dalam post-test mengarah pada temuan utama dari penelitian ini. Dengan dilengkapi hasil dari dependent t-test dan Ukuran Efek, dapat disimpulkan bahwa penggunaan Bot Werewolf Telegram berpengaruh positif terhadap peningkatan penguasaan kosakata siswa SMA. 
Beriringan dengan hasil tes yang telah disajikan dalam paragraf di atas, proses yang telah dilalui siswa selama enam sesi pembelajaran Bot Werewolf Telegram juga akan dibahas di sini. Selama sesi, percakapan tertulis direkam dalam bentuk tangkapan layar dan arsip obrolan. Pada pertemuan pertama setelah pre-test dilaksanakan, siswa diarahkan untuk hadir di grup chat Telegram. Mekanisme permainan diperkenalkan saat siswa diberi pengarahan tentang tujuan pembelajaran mengenai kosakata yang akan dipelajari. Dari 30 siswa, 10 siswa pertama memulai gameplay siklus pertama. Begitu seterusnya sampai 10 siswa terakhir mendapatkan kesempatan bermain dalam permainan yang dipandu oleh Bot Werewolf Telegram.

Setelah terlibat dalam enam sesi Bot Werewolf Telegram, penguasaan kosakata siswa diukur dalam post-test. Data skor hasil post-test menunjukkan indikasi bahwa penguasaan kosakata dalam hal keluasan kosakata tidak menjamin performa yang baik dalam mengerjakan bagian pilihan ganda berbasis teks. Temuan yang mirip juga ditemukan pada penelitian Bhakti (2017) yang mencoba mengukur penguasaan kosakata siswa melalui storytelling. Di penelitian tersebut ditemukan bahwa penguasaan kosakata siswa tinggi tidak menjamin bahwa siswa akan mampu melakukan storytelling yang baik. Hal ini menunjukkan bahwa penguasaan kosakata lebih kompleks daripada proses perolehan kosakata.

Padahal, penelitian terdahulu menemukan bahwa penguasaan kosakata meningkatkan pemahaman membaca siswa. McWhorter (1992) menyatakan bahwa penguasaan kosakata meningkatkan pemahaman membaca secara signifikan ketika siswa menggabungkan berbagai strategi dalam pemahaman bacaan. Penguasaan kosakata dianggap memberikan kontribusi positif dan signifikan terhadap pemahaman bacaan. Hal ini ditegaskan dalam penelitian lain oleh Furqon (2013) yang menunjukkan bahwa ada korelasi yang kuat antara penguasaan kosakata dan pemahaman bacaan. Korelasi menyiratkan bahwa memiliki sejumlah kosakata membuat siswa memahami teks dengan mudah. Jika dibandingkan dengan temuan penelitian saat ini dan Bhakti (2017), ini menunjukkan ada faktor-faktor lain yang membuat penguasaan kosakata yang baik tidak menjamin performa baik dalam keahlian reseptif siswa.

Selain Bot Werewolf, ada beberapa komponen pendukung pembelajaran lain yang ada di Telegram. Karimov dan Kim (2017) menemukan bahwa dalam grup chat Telegram, kutipan obrolan dan lampiran yang berisi berkas multimedia, jajak pendapat, serta lokasi GPS dapat memengaruhi perilaku siswa dari segi harapan kinerja, partisipasi kelas, dan pemahaman materi. Fitur-fitur tersebut secara signifikan memengaruhi perilaku pengguna. Bahkan, penggunaan stiker di Telegram juga mempengaruhi pembelajaran kosakata (Ghobadi \& Taki 2018). Dua penelitian lain pun mengungkapkan bahwa penggunaan Telegram memfasilitasi perolehan pola tekanan kata (Khodarahmi \& Heidari-Shahreza, 2018; Tabrizi \& Onvani, 2018). Berdasarkan arsip obrolan aktivitas siswa di grup chat pada penelitian ini, penggunaan kutipan obrolan, lampiran, dan stiker sepertinya memang membantu memberi warna pada pembelajaran dan memfasilitasi kosakata yang berkaitan dengan kata sifat ekspresif. Namun, perolehan pola tekanan kata menjadi batasan dalam penelitian saat ini, sebab penguasaan kosakata siswa terbatas pada jangkauan konteks kemampuan reseptif membaca.

Sebagai tambahan mengenai keaktifan siswa, penelitian oleh Hakim (2019) menunjukkan bahwa siswa di kelas satu SMP lebih proaktif dalam proses pembelajaran menggunakan Telegram. Mereka menikmati kegiatan kosakata asalkan guru terampil dalam menyampaikan prosedur menggunakan Telegram. Sikap proaktif juga terlihat pada siswa di kelas satu SMA. Mereka tidak ragu untuk bertanya dalam rangka memahami bagaimana permainan Werewolf bekerja. Pada tingkatan lebih tinggi, hal ini juga memupuk otonomi belajar siswa saat mereka dibiarkan berinteraksi sendiri dengan Bot Werewolf Telegram. Mengenai hal ini, Radfar (2017) menemukan bahwa platform TIK secara signifikan memainkan peran penting dalam belajar kosakata terutama dalam membangun motivasi dan 
otonomi pelajar. Terungkap bahwa kosakata dan TIK adalah bagian penting dari pembelajaran bahasa karena arti kata baru cenderung diperkenalkan di buku teks dan ruang kelas yang difasilitasi oleh teknologi.

Pengajaran kosakata melalui teknologi dapat diwujudkan dalam beberapa cara. Sebagian besar dengan cara melibatkan semi-kontekstualisasi dan kontekstualisasi penuh kosakata. Tidak seperti mencari kosakata di internet dan mempresentasikannya di kelas, dalam sesi pembelajaran Bot Werewolf Telegram, guru diharapkan memiliki strategi untuk kontekstualisasi penuh kosakata ke dalam teks dengan fitur kustomisasi bot yang ada. Untuk mengatasi hal ini, Dalton dan Grisham (2011) mengusulkan strategi tentang cara menggunakan TIK di kelas dalam paragraf berikut.

Pertama, akan sangat bagus jika siswa memiliki ruang saat menggunakan media dalam mengekspresikan pengetahuan kosakata. Dalam sesi Bot Werewolf Telegram, mereka bisa tetap melatih kosakata mereka di luar alokasi jam pelajaran. Kemudian, mereka harus belajar dari tampilan visual kata-kata dan hubungannya dengan teks. Maka dari itulah stiker Telegram pun berperan dalam pembelajaran kosakata siswa. Lebih lanjut lagi, Dalton dan Grisham (2011) menambahkan bahwa membaca teks digital juga meningkatkan volume membaca siswa. Dengan Bot Werewolf, siswa dituntun membaca sebagai bagian dari permaian. Akhirnya, berbagai aktivitas dapat digunakan untuk menghubungkan antara kegembiraan dan pembelajaran dalam permainan kosakata online yang terfasilitasi oleh panduan Bot Werewolf di Telegram ini.

Sebagai media pembelajaran, Telegram menyediakan sistem penyimpanan berbasis cloud yang masif untuk menyimpan file. Fitur ini dirasa berguna baik bagi guru maupun siswa karena file-file tersebut tidak menghabiskan penyimpanan di ponsel mereka. Hal ini sejalan dengan Alhawiti (2015) yang menegaskan bahwa pembelajaran bahasa dengan sumber materi yang mudah diakses berpengaruh positif terhadap prestasi belajar siswa dalam konteks ESP. Oleh karena itu, Telegram dipandang sebagai wadah untuk menyelenggarakan kelas online kolaboratif. Dengan lusinan bot asisten, Telegram memberi guru kemampuan untuk mengatur bahkan membuat bot sendiri yang disesuaikan untuk tujuan pembelajaran. Dengan demikian, dibandingkan dengan messenger lain, Telegram berfungsi sebagai platform ringkas yang tidak terlalu bergantung atau perlu diintegrasikan dengan aplikasi lain, melainkan sangat adaptif untuk dipadukan dengan teknik atau metode lain seperti dalam blended learning (Wahyuni, 2016). Kemungkinan besar, keserbagunaan dan keramahan pengguna membuat Telegram sangat populer di kalangan guru dan siswa, terutama dalam masa pandemi. Semua diskusi di atas tampaknya mengarah pada kesimpulan bahwa Telegram adalah aplikasi pesan instan yang mudah diadaptasi dan serbaguna untuk membantu pembelajaran bahasa jarak jauh dalam konteks EFL Indonesia.

Pembahasan mengenai pengaruh penggunaan Bot Werewolf Telegram telah menunjukan bahwa kegiatan belajar mengajar dalam Telegram tampaknya perlu digali lebih dalam sebagai proses pengalaman belajar kosakata siswa yang bermakna. Oleh karena itu, ada beberapa aspek yang perlu dieksplorasi dengan analisis kualitatif untuk penelitian lebih lanjut mengenai keseluruhan proses implementasi Bot Werewolf Telegram, bukan hanya berfokus pada hasil pembelajaran sebagai produk utama seperti yang banyak disarankan oleh penelitian sebelumnya. Dengan mempertimbangkan tiap level pendidikan dan ekspektasi penguasaan kosakatanya, proses belajar dalam platform Telegram akan menggambarkan keterlibatan interaksi guru dan siswa, birokrasi lembaga pendidikan serta literasi digital dan budaya yang lebih luas dalam berbagai konteks masyarakat (Kayzouri et al., 2020). Maka dari itu, penelitian lebih lanjut sangat diperlukan untuk mendapatkan gambaran yang jelas mengenai karakteristik kosakata dalam pembelajaran tingkat mikro, meso, dan makro melalui implementasi Bot Werewolf Telegram di institusi pendidikan. 
Analisis Karakteristik Kosakata

Angka-angka yang mewakili penguasaan kosakata siswa dalam skor post-test mungkin bisa mencerminkan keterampilan berbahasa siswa yang dinilai dalam butir soal tertentu. Misalnya, dalam bagian tes kedalaman kosakata, siswa mungkin telah menghubungkan kata tertentu dalam kalimat yang disediakan dalam pertanyaan untuk membuat makna. Namun, ketika kosakata tersebut menjadi bagian dari teks naratif, cara siswa mengartikan kata-kata dalam membuat makna akan berbeda berdasarkan adegan dalam teks. Hal ini karena sebuah teks memberikan kata-kata yang lebih banyak bagi mereka untuk memvisualisasikan adegan yang disajikan. Keadaan ini ditegaskan oleh Taylor and Perfetti (2016) yang menyatakan bahwa perbedaan penguasaan dan pemahaman kosakata dapat meningkatkan kemampuan siswa dalam mengidentifikasi dan menguraikan kata. Adapun bagi peserta yang mendapat skor di bawah rata-rata, aspek yang layak disebutkan adalah bagaimana kosakata asing mungkin berperan dalam kognisi pelajar. Meskipun kosakata instruksional berfungsi sebagai input dalam database Werewolf Telegram Bot, kosakata yang benar-benar baru dapat menyebabkan kecemasan dalam kecepatan sesi pembelajaran yang dipimpin oleh bot (Rajab et al., 2012). Selain itu, pendapat ini didukung oleh pernyataan Azadi dan Azad (2017) bahwa pembelajaran mobile dan elektronik akan pula berpengaruh terhadap kecepatan membaca dan pemahaman membaca siswa.

Selanjutnya, dalam hal karakteristik kosakata, chat log Telegram menunjukkan penggunaan kosakata siswa SMA lebih banyak berhubungan dengan sinonim dalam rasa keterikatan yang ada pada kerangka analisis British National Corpus Nation (2001). Rasa keterkaitan kata-kata dalam teks yang digunakan dalam sesi Werewolf Telegram tercermin dalam kata-kata berulang yang mewakili makna yang sama. Kata-kata ini biasanya menjadi kata kunci yang menyusun gagasan utama paragraf atau topik utama paragraf. Hal ini sejalan dengan salah satu strategi pemahaman bacaan di mana siswa harus mencari kata-kata yang digunakan berulang kali di dalam paragraf dalam suatu bacaan.

Terlebih lagi, implikasi dari munculnya kosakata dalam kerangka analisis ini dapat dilihat pada bagian-bagian yang digunakan dalam UTBK. Dalam ujian ini, artikel ilmiah berfungsi sebagai bagian otentik yang disesuaikan untuk butir soal. Ketika teks berisi kelompok kata sebagai klausa dependen, biasanya siswa dapat mengabaikan klausa dan langsung ke klausa independen karena klausa independen biasanya memiliki gagasan utama kalimat. Hal ini paling efektif terutama ketika kalimatnya panjang dan relatif lebih sulit untuk dipahami.

Secara umum, penggunaan kosakata oleh siswa dalam sesi Werewolf Telegram dianggap sejalan dengan tujuan instruksional yang mengharuskan siswa untuk menguasai kosakata yang ditentukan dalam buku teks yang direkomendasikan oleh kurikulum. Namun demikian, menurut Hunt dan Belgrar (2005) teks otentik idealnya disesuaikan dengan kerangka kerja tertentu yang memastikan bahwa: (1) apa yang siswa pelajari di kelas sejalan dengan tujuan instruksional; dan (2) kosakata yang disajikan dalam butir-butir soal mengukur apa yang seharusnya diukur oleh tes tersebut. Untuk alasan ini, penting untuk melihat kerangka pengembangan kosakata membaca EFL sehingga guru dapat mempertimbangkan keterampilan penting yang dibutuhkan oleh siswa.

\section{KESIMPULAN}

Pada penelitian ini, dapat disimpulkan bahwa pengaruh Bot Werewolf Telegram diwakili oleh nilai $t$ yang diperoleh. Nilai $t$ mengacu pada angka yang diperoleh dari perhitungan independent t-test dua arah dengan menggunakan data dari grup eksperimental dan kontrol. Statistik deskriptif menunjukkan bahwa terdapat distribusi skor yang normal dan varians yang homogen di antara grup eksperimental dan grup kontrol baik dalam pre-test dan post-test. Hasil independent t-test pada posttest mengindikasikan terdapat perbedaan signifikan dari penggunaan Bot Werewolf Telegram dan placebo treatment pada penguasaan kosakata siswa SMA di taraf signifikansi 0.05 dengan $\mathrm{p}=0.011<$ 
0.05 pada $\mathrm{df}=29$. Selanjutnya, hasil dependent $t$-test dan Ukuran Efek mengindikasikan bahwa terdapat perbedaan signifikan di antara skor pre-test dan post-test yang dihasilkan siswa SMA di grup eksperimental dengan kekuatan ukuran efek relatif taraf medium dari treatment Bot Werewolf Telegram.

Berdasarkan temuan karakteristik kosakata dalam studi ini, peneliti merekomendasikan para pendidik dan peserta didik untuk memperoleh lebih banyak paparan terhadap teknologi terdepan yang disebut bot dalam pengajaran bahasa Inggris sebagai bentuk kompetensi literasi digital dan kultural dalam TIK. Begitu pula bagi para pembuat kebijakan diharapkan untuk mengadakan uji kelayakan mengenai teknologi yang dapat diterapkan dalam menyesuaikan penguasaan kosakata siswa SMA dengan tujuan-tujuan instruksional dalam kurikulum. Beberapa gagasan dalam kesimpulan ini menjadi batasan penelitian karena pilihan metodologis yang terkendala oleh pandemi, terutama dalam mensosialisasikan Telegram dan Bot Werewolf kepada siswa sebagai teknologi baru. Dalam sesi Werewolf Telegram, terungkap bahwa sebelum mengadaptasi teknologi ini ke dalam kelas, guru harus terbiasa dengan seluruh mekanisme dan pengoperasian bot di Telegram. Jika memungkinkan, mereka perlu diberi pengarahan dan dilatih untuk melakukan beberapa sesi Telegram Werewolf sebelum benarbenar menerapkan teknik ini di kelas mereka sendiri.

Jika hal-hal tersebut di atas tidak dilakukan, pengaruh Bot Werewolf Telegram mungkin tidak maksimal. Akibatnya, kosakata yang harus dipelajari dengan baik oleh siswa akan dibayangi oleh cerita naratif yang hanya disajikan oleh bot. Alangkah baiknya jika sebelum mengajar di kelas, guru berlatih dengan rekan atau melakukan uji coba untuk melihat bagaimana instruksi bekerja dengan siswa. Sebagai tambahan, hal lain yang perlu diperhatikan selama sesi adalah kemampuan mengelola siswa dalam alokasi waktu yang terbatas, mengadaptasi materi buku teks ke dalam bot, dan menyaring kosakata yang representatif untuk siswa, sehingga mereka dapat mempelajari kosakata sesuai dengan tujuan instruksional kurikulum SMA.

\section{DAFTAR PUSTAKA}

Abu-Ayfah, Z. (2019). Telegram app in learning English: EFL students' perceptions. English Language Teaching, 13(1), 1-51. https://doi.org/10.5539/elt.v13n1p51.

Alakrash, H. M., Razak, N. A., \& Bustan, E. S. (2020). The effectiveness of employing Telegram application in teaching vocabulary: A quasi experimental study. Multicultural Education, 6(1), 151-159. https://doi.org/10.5281/zenodo.3905099.

Alhawiti, M. (2015). The Effect of Mobile Language Learning on ESP Students' Achievement. Journal of Modern Education Review, 5(3), 272-282.

Amry, A. (2014). The impact of using WhatsApp mobile learning activities on the achievement and attitudes of online students using mobile devices at the university. European Scientific Journal August, 10(22).

Azadi, M., \& Azad, M. (2017). On the effect of mobile and electronic learning (ME learning) on reading rate and reading comprehension of Iranian elementary EFL learners. Proceedings of the 15th International TELLSI Conference. Islamic Azad University.

Bhakti, S. (2017). Vocabulary Mastery by Using Storytelling. Journal of Linguistic and English Teaching, 88-89.

Cakir, I. (2015). Opinions and Attitudes of Prospective Teachers for the Use of Mobile Phones in Foreign Language Learning. Contemporary Educational Technology, 6(3), 72-76.

Cohen, J. (1992). Statistical Power Analysis for the Behavioral Sciences. Lawrence Erlbaum Associates. 
Dalton, B., \& Grisham D. (2011). eVoc Strategies: 10 ways to use technology to build vocabulary. The Reading Teacher, 64(5), 306-317. International Reading Association.

Faramarzi, S., Tabrizi, H, H., \& Chalak, A. (2019). Telegram: an instant messaging application to assist distance language learning. Teaching English with Technology, 19(1), 132-147.

Furqon, F. (2013). Correlation between Students' Vocabulary Mastery and Their Reading Comprehension. Journal of English Education, 1(1), 68-80.

Ghobadi, S., \& Taki, S. (2018). Effects of Telegram stickers on English vocabulary learning: Focus on Iranian EFL learners. Research in English Language Pedagogy, 6(1), 139-158.

Hakim, M. F. F. (2019). The use of Telegram to facilitate students' vocabulary learning at SMPN 1 Surabaya. [Bachelor paper, UIN Sunan Ampel]. UIN Sunan Ampel Digital Library. http://digilib.uinsby.ac.id/id/eprint/32611.

Hunt, A., \& Beglar, D. (2005). A framework for developing EFL reading vocabulary. Reading in a Foreign Language, 17(1), 24-59.

Karimov, O., \& Kim, H. (2017). Factors of UTAUT affecting the user behavior based on Telegram application in Uzbekistan. Asia-Pacific Journal of Multimedia Services Convergent with Art, Humanities, and Sociology, 7(12), 831-840.

Kayzouri, A. H., Mohebiamin, A., Saberi, R., \& Bagheri-Nia, H. (2020). English language professors' experiences in using social media network Telegram in their classes: A critical hermeneutic study in the context of Iran. Qualitative Research Journal, 21(2), 124-134. https://doi.org/10.1108/QRJ-02-2020-0008.

Khodarahmi, Z., \& Heidari-Shahreza, M. A. (2018). Effect of MALL on the acquisition of word stress patterns of English by Iranian EFL learners: The case of Telegram. Journal of Applied Linguistics and Language Research, 5(1), 40-55.

Mashhadi H. D., \& Kaviani, M. (2016). The Social impact of Telegram as a social network on teaching English vocabulary among Iranian intermediate EFL learners (Payam Noor Center). Journal of Sociological Studies of Youth, 7(23), 65-76.

McWhorter, T. (1992). College Reading and Study Skills. Niagara Country Community College.

Movafagh, A. E. (2017). The effect of using Telegram messenger on vocabulary learning of Iranian EFL learners. Language Education Studies, 3(4), 1-9.

Nafis, M., Faridza., \& Melor. (2018). Enhancing English language learning and teaching via Qgram (Telegram and Quizlet) innovation. International Journal of Academic Research in Progressive Education and Development, 7(4), 435-446. http://dx.doi.org/10.6007/IJARPED/v7-i4/5344.

Nation, I. S. P. (2001). Learning vocabulary in another language. Cambridge University Press.

Niyayesh, U. (2015). Number of Iranian using Telegram mobile app increases to 13 million. Trend News Agency. Azerbaijan.

Prensky, M. (2001). Digital Natives, Digital Immigrants. On the Horizon Report. NCB University Press.

Taylor, J. N., \& Perfetti, C. A. (2016). Eye movements reveal readers' lexical quality and reading experience. Reading and Writing, 29, 1069-1103.

Radfar, Z. H. (2017). The effects of ICT-based learning on students' vocabulary mastery in junior high schools in Bandung. International Journal of Education, 10(2), 149-156.

Rajab, A., Zakaria, W. Z. W., Rahman, H. A., Hosni, A. D., \& Hassani, S. (2012). Reading anxiety among second language learners. Procedia - Social and Behavioral Sciences, 66, 362-369.

Sugiyono. (2017). Metode penelitian kuantitatif, kualitatif, dan R\&D. Alfabeta. 
Syakriah, A. (2019, November 19). Changes to state university admission keep students on edge. The Jakarta Post. https://www.thejakartapost.com/news/2019/11/19/changes-to-state-universityadmission-keep-students-on-edge.html.

Wahyuni, S. (2016). The Effect of Blended Learning Model towards Students' Writing Ability. Journal of English for Academic, 5(2). 97-110.

Wiranegara, D. A., \& Hairi, S. (2020). Conducting English learning activities by implementing Telegram group class during Covid-19 pandemic. Journal of Teaching English for Academic and Specific Purposes, 3(2), 104-114. https://doi.org/10.18860/jeasp.v3i2.11122.

Xodabande, I. (2017). The effectiveness of social media network Telegram in teaching English language pronunciation to Iranian EFL learners. Cogent Education, 4(1). 1-14. https://doi.org/10.1080/2331186X.2017.1347081. 